\title{
Gender differences in cooperation with group membership
}

\author{
Gary Charness and Aldo Rustichini
}

March 24, 2010

\begin{abstract}
We study experimentally how males and females differ in the way same-gender peers observing their action affects their social behavior. In our experiment, people play a Prisoner's Dilemma Game with a partisan audience watching the choice. Two groups of the same size (6-10 persons) participated in each session; these groups could be both all-male, both all-female, or one allmale and one all-female. Groups were separated into two rooms. Each person in the group played the game once with an audience of the same group ("at home") and once with audience of the other group ("away”). Participants additionally received a 1/3 share of the active group member's payoffs in games in which they made no choices.

Behavior is significantly affected by the interaction of gender and place: males cooperate substantially more often when away, while females cooperate substantially more often when at home. At home, females cooperate significantly more than males, and when away the cooperation rates are similar. We confirm the established result in the literature that there is no gender difference in aggregate cooperation rates in Prisoner's Dilemma, but in our environment this is an artifact produced by the balance of two opposing forces.

We discuss a possible explanation for this pattern: Males and females wish to signal their ingroup peers, but males wish to signal their formidability and females wish to signal their cooperativeness.
\end{abstract}

Keywords: Group membership, Gender differences, Cooperation

Acknowledgments: We thank Leda Cosmides, Andrew Delton, Daniel Fessler, Melanie MacEacheron, Karthik Panchanathan and seminar participants at the UCLA Behavior, Culture, and Evolution for very helpful comments.

\section{Contact:}

Gary Charness, Department of Economics, University of California at Santa Barbara, charness@econ.ucsb.edu, 2127 North Hall, UCSB, Santa Barbara, California, 93106-9210, 805-8932412, 805-893-8830 (fax)

Aldo Rustichini, Department of Economics, University of Minnesota, arust@econ.umn.edu, 4-101 Hanson Hall, 1925 Fourth Street South, Minneapolis, MN 55455, 612-625-4816, 612-274-0209 (fax) 


\section{Introduction}

How does the presence of others influence social behavior? Is this influence different across genders, and if so why? The interest of the question is twofold. First, most games are not played in isolation but involve witnesses to our social behavior; such an audience may be friendly or adversarial. Social observation may affect our behavior in addition to the predictions we make about the behavior of others. Second, the effect of this social observation may shed light on the reason for possible gender difference in strategic behavior.

Gender differences in social dilemmas have been analyzed experimentally (e.g. Simpson (2003), Kuwabara (2005). Rapoport and Chammah (1963) first posed the question, and the literature is surveyed in Ledyard (1995)). A robust finding in this literature is that differences in social choice are weak or absent (Ledyard, (1995), Sell (1997)). These results pose a puzzle, as they conflict both with an ex-ante expectation and with differences that have been found in individual choice, as for example in choices under risk (Spigner, Hawkins and Lorens (1993), Flynn, Slovic and Mertz, (1994), Charness and Gneezy, (2009)). In these experiments, players make their choices in isolation.

In the past decade, there has been a considerable increase in interest in gender differences. A comprehensive review can be found in Croson and Gneezy (2009). Previous work has indicated that women are less "competitive" than men, suggesting a possible explanation for the well-known malefemale wage differential in labor markets. In the experiments underlying the studies, the environment is characterized by a payment scheme, which is called competitive if the payment depends on the performance of the individual relative to that of other participants. Findings (Gneezy, Niederle, and Rustichini (2003), Gneezy and Rustichini (2004), and Niederle and Vesterlund (2007)) show an improvement in performance with homogeneous gender groups when the payment scheme becomes 
competitive. This improvement is smaller for females, who are also less likely to choose a competitive scheme when they are given a choice.

However, no study has considered behavior in games when the people making strategic choices are in same-gender groups when their peers can observe the choices made. We adapt the experimental design in Charness, Rigotti, and Rustichini (2007) to investigate this issue. That paper investigated the effect of group membership on individual behavior in games. There were no significant differences in behavior for males and females. However, the groups in that study were comprised of a mix of males and females; it is entirely possible that behavior is qualitatively different when each group is homogeneous with respect to gender. There does not appear to be any economic theory, of the type that is available as a foundation of gender differences in risk attitude (as in Dekel and Scotchmer (1999), Robson (1996a), Wärneryd (2002)),that would help us to predict different behavior for males and females in this environment. However, if we believe that females are less competitive, we might expect a higher frequency of cooperation for women.

The experiment was conducted with students (primarily undergraduates) at the University of California at Santa Barbara. In each period, two players (one from each room) were seated on opposite sides of a table in each of the two rooms. Hence, one of the participants was playing in front of an audience of in-group members (a condition we call for convenience "at home') and the other in front of an audience of out-group members ("away”). They simultaneously selected a choice by sliding one of two cards face down to the experimenter, who then revealed the choices by turning the cards over. Participants not actively making a choice were seated behind the home player and serve as an audience. Participants received $1 / 3$ of the payoffs from each outcome in which they did not make a choice, as well as full payoffs from the outcomes resulting from their own choices. Each 
person played once at home and once away. Groups were gender homogeneous, either all-male or all-female.

We find little difference in the overall cooperation rates for males and females, replicating the result in the literature (Simpson (2003), Kuwabara (2005)) that there are no differences in cooperation rates across genders. Nevertheless, we observe large and significant differences in the patterns in behavior across gender depending on whether one is playing at home or away. Males are significantly less cooperative at home than they are away, while females are significantly more cooperative at home than away. At home, females cooperate significantly more than males, and the cooperation rates are similar when away. The lack of a difference in cooperation across gender is found to be an artifact of the balance between effects of place (at home and away) and gender.

We propose an explanatory theory that is based on signaling one's personal characteristics to one's in-group members, as social bonds are important. Our theory borrows ideas from the literature on evolutionary psychology and social psychology. The essence of this theory is that while both males and females wish to gain the approval of their in-group members, the actions that are socially desirable differ across gender. Males wish to signal that they formidable, while females wish to signal that they are cooperative. These conjectures suggest differences that are inherent to genders (just as differences in attitude to risk), and if confirmed would make complete formal evolutionary explanations desirable.

The remainder of the paper is organized as follows. We present the details of our experimental design in section 2, and report our results in section 3. Our theory and the related literature are described in section 4 . We offer some discussion in section 5 , and section 6 concludes. 


\section{Experimental Design}

Participants were recruited by e-mail from a general database of students at the University of California at Santa Barbara who had registered as being interested in participating in paid experiments; there were 12-20 people in each session. The number of participants was always an even number, which depended on how many participants were actually present at the beginning of the experiment. The Prisoner's Dilemma game played is shown below: entries denote payoff units, with each unit worth $\$ 0.50$ in actual money.

\section{Prisoner's Dilemma}

\begin{tabular}{|c|c|c|}
\hline & A & B \\
\hline A & 5,5 & 1,7 \\
\hline B & 7,1 & 2,2 \\
\hline
\end{tabular}

Actions were labeled simply A and B; in the analysis we will refer to the choice of A as cooperation and B as defection, as usual in the interpretation of the game. There were 15 sessions overall. Five sessions were all-male, with both groups consisting of exclusively male participants, while five sessions were all-female. In the other five sessions, one group was all-male and the other group was all-female. No participant attended more than one session. Overall, there were 234 participants (120 female and 114 male), who earned an average of about \$16 (including a show-up fee) for a little less than an hour. A complete set of instructions can be found in Appendix A.

Participants initially all met in the same room, and they were randomly assigned to either the Row group or the Column group for the duration of the session. Row players went to a room labeled Room R, while Column players went to a different room labeled Room C; these labels (Row and Column respectively) were prominently displayed on the blackboards of the respective rooms. 
In each room, participants received instructions that explained how play would proceed (see instructions are presented in Appendix A). Numbered slips of paper were drawn in each room to determine the period in which each person was going to play in Room R and Room C. At the beginning of a period, a Row player sat on one side of a table in Room $\mathrm{R}$ while a Column player who arrived from Room C sat across the table. The complementary scenario (with labels switched) took place simultaneously in Room C. One can consider the Row player to be at home in Room R and the Column player to be away in that same room. These labels are used purely for convenience, and do not denote acceptance of any specific interpretation of behavior. In each room, group members at home in that room were seated in a semi-circle behind the active member of their group and could observe both players; thus, Row players are the audience in Room R and Column players are the audience in Room C. All participants were required to observe strict silence at all times.

In each period, an experimenter in the room placed two opaque index cards face down on the table; one card had " $\mathrm{A}$ " written on the other side, while the other card had " $\mathrm{B}$ " written on the other side. Each player examined these cards and made a choice by passing the card face down to the experimenter. The experimenter then revealed the outcome to everyone in the room by flipping over the two cards simultaneously and immediately after receiving the cards. At the end of the period, the away participant went back to the room from which he or she had arrived. The experiment continued for as many periods as needed until each player had made a choice in each room, once at home and once when away.

The final payoff to participants was the sum of two components: the outcome of the two games one played and the outcome of all the games played by one's group members. The first component equals the sum of the payoffs in those two games. The second component equals $1 / 3$ of the sum of the payoffs received by the active players in one's group, only for the periods when one 
was not an active player. These rules were clearly explained to the participants prior to the commencement of play.

\section{Experimental Results}

The dependent variable of greatest interest is the cooperation rate, which is the fraction of A choices. Table 1 summarizes the aggregate cooperation rates for males and females, depending on the type of session and whether they are at home or away. Complete results for each individual session are shown in Appendix B.

Table 1: Aggregate Cooperation Rates.

Number of times the participant chose A and total number of choices.

\begin{tabular}{|c|c|c|c|}
\hline & Home & Away & Combined \\
\hline \multirow{2}{*}{ Males in homogenous sessions } & $\begin{array}{c}21 / 76 \\
(27.6 \%)\end{array}$ & $\begin{array}{c}34 / 76 \\
(44.7 \%)\end{array}$ & $\begin{array}{c}55 / 152 \\
(36.2 \%)\end{array}$ \\
\hline \multirow{2}{*}{ Males in mixed sessions } & $12 / 38$ & $14 / 38$ & $26 / 76$ \\
& $(31.6 \%)$ & $(36.8 \%)$ & $(34.2 \%)$ \\
\hline \multirow{2}{*}{ Males, overall } & $33 / 114$ & $48 / 114$ & $\mathbf{8 1 / 2 2 8}$ \\
& $(28.9 \%)$ & $(42.1 \%)$ & $(35.5 \%)$ \\
\hline \multirow{2}{*}{ Females in homogenous sessions } & $36 / 82$ & $24 / 82$ & $60 / 164$ \\
& $(43.9 \%)$ & $(29.3 \%)$ & $(36.6 \%)$ \\
\hline \multirow{2}{*}{ Females in mixed sessions } & $19 / 38$ & $15 / 38$ & $34 / 76$ \\
& $(50.0 \%)$ & $(39.5 \%)$ & $(44.7 \%)$ \\
\hline \multirow{2}{*}{ Females, overall } & $55 / 120$ & $39 / 120$ & $\mathbf{9 4 / 2 4 0}$ \\
& $(45.8 \%)$ & $(32.5 \%)$ & $\mathbf{( 3 9 . 2 \% )}$ \\
\hline
\end{tabular}

The overall cooperation rates (in bold) for males and females are similar, 35.5\% and 39.2\% respectively. The test of the difference of proportions (see Glasnapp and Poggio (1985)) finds no significant difference in these cooperation rates $(Z=0.81, p=0.418$; all statistical tests are two-tailed, unless otherwise indicated). The difference is even smaller in gender-homogenous sessions, with overall cooperation rates of $36.2 \%$ for males and $36.6 \%$ for females. Thus, we see no evidence of differences in average cooperation across gender, if we average over the different conditions. 
However, this similarity in average behavior is the result of a balancing of significant effects of the interaction of role and gender. If we look at behavior in similar situation of males and females, we find that males cooperate significantly less when at home than do females (28.9\% versus $45.8 \%$, with $Z=2.67, p=0.008)$. Males cooperate more when away than do females ( $42.1 \%$ versus $32.5 \%)$, but this difference is not statistically significant, with $Z=1.52, p=0.129$. The cooperation rate for males is 13.2 percentage points higher when away than when at home (42.1\% versus $28.9 \%$ ), while the cooperation rate for females is 13.3 percentage points lower when away than when at home (45.8\% versus 32.5\%). Both of these differences are statistically significant, with $Z=2.08, p=0.038$, and $Z=-2.12, p=0.035$, respectively.

If we consider the gender composition of participants in the session, we find that the cooperation rate in all-male sessions is 17.1 percentage points higher when away than at home (44.7\% versus $27.6 \%$ ); this difference is significant, with $Z=2.19, p=0.028$. This pattern is reversed in all-female sessions, with a cooperation rate 14.6 percentage points higher when at home than when away; the test of the difference of proportions gives $Z=-1.95, p=0.051$. In the mixed-gender sessions, these results go in the same directions, but are of smaller size and not significant; we have $Z$ $=0.48, p=0.631$ for males in mixed-gender sessions and $Z=-0.92, p=0.358$ for females in mixedgender sessions.

These tests do not take into account the possible simultaneous interaction between gender and role at home and away. In Table 2, we present the marginal effects estimated from a logit regression, after clustering on each individual participant to take into account the fact that we have two observations for each participant. 


\section{Table 2: Marginal effects from the Logit Regression for Cooperation}

\begin{tabular}{|c|c|}
\hline & Cooperate \\
\hline Female Away & $\begin{array}{c}-0.126^{* * *} \\
(0.048)\end{array}$ \\
\hline Male Home & $\begin{array}{c}-0.160^{* * *} \\
(0.056)\end{array}$ \\
\hline Male Away & $\begin{array}{c}-0.035 \\
(0.060)\end{array}$ \\
\hline $\mathrm{N}$ & 468 \\
\hline Log-pseudolikelihood & -304.61 \\
\hline
\end{tabular}

*** indicates significance at $p=0.010$. Standard Errors are in parentheses.

The omitted category is the female cooperation rate when at home.

The regression confirms that females cooperate significantly less when away than when at home (a reduction of 12.6 percentage points), and male cooperate significantly less when at home than do females (a difference of 16.0 percentage points); both of these differences are significant at $p$ $=0.010$. There is no significant difference between the cooperation rates for females when at home and males when away.

Checking for the robustness of the results, one might argue that while each individual makes only one choice in each environment, each individual's decision is not independent, since an individual has observed previous outcomes when at home. The most conservative statistical test considers each session as one independent observation for each gender's cooperation rates (for both genders, there are five same-gender and five mixed-gender sessions). As can be seen from Appendix $\mathrm{B}$, cooperation rates for males were higher when they were away in eight of the 10 sessions and lower in one of the 10 sessions (the rates were the same in the other session). A simple binomial test indicates statistical significance $(Z=2.06, p=0.040)$. Similarly, cooperation rates for females were lower when they were away in seven of the 10 sessions and higher in two of the 10 sessions; 
however, here the difference is not statistically significant with session-level data $(Z=-1.34, p=$ 0.180). Finally, we can calculate the difference in home and away cooperation rates for each session and compare these across gender. A Wilcoxon-Mann-Whitney ranksum test gives $Z=2.67, p=$ 0.008, so that even the most conservative test indicates strongly that the male and female patterns across roles are different.

Given the possibility that participants may be influenced by previous choices by group members, we then check whether this behavior changed significantly over time, a question that has additional independent interest. For this, we analyze (see Figure 1) the rate of cooperation at home over time for males and females:

Figure 1: Cooperation rate at home over time

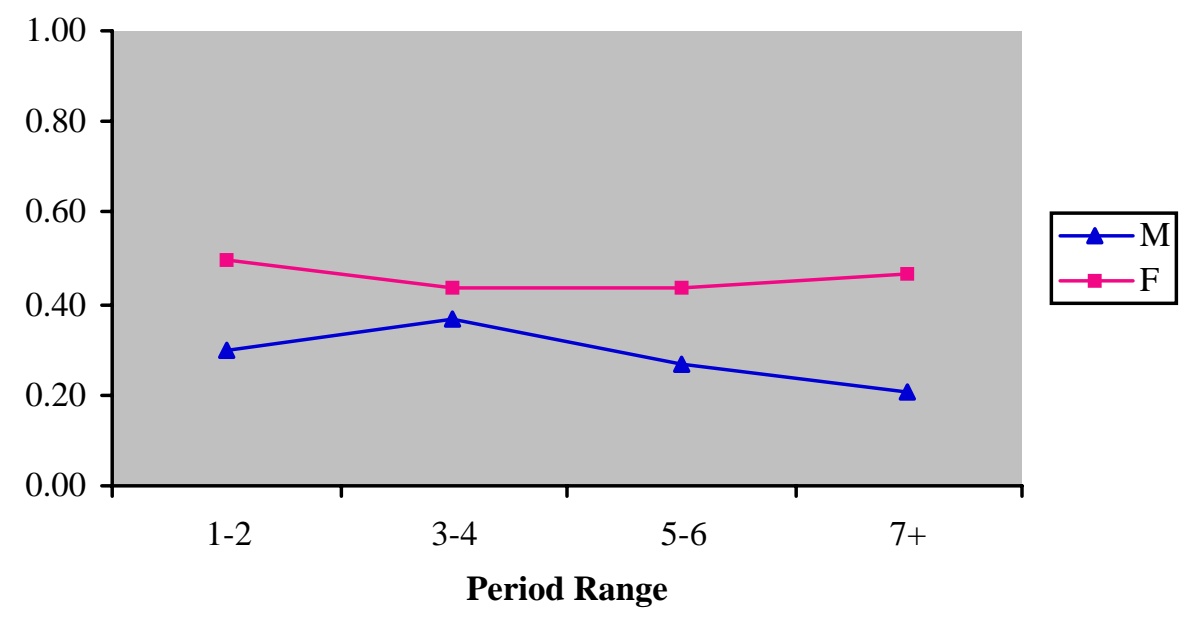

There is a slight decline in cooperation rate for males, and no time trend in female cooperation rate. To analyze significance of the trends, we run a panel data logit analysis of the effect of the past periods on choice. This confirms that the time trend exists for males playing at home: cooperation rate falls by an estimated 1.4 percentage points every period; the interaction of male gender with the number of periods is negative and significant $(\mathrm{Z}=-2.58, p=0.010$ ), while the period variable is not 
( $\mathrm{Z}=0.01, p=0.996$ ), thus strengthening over time the negative effect on cooperation of male gender playing at home. The effect is not significant for individuals (male or female) playing when away.

A further check on the robustness of the results is obtained by looking at the correlation between the choices in one period and the next. Recall that participants only observe the host choices of members of their group. The correlation between host cooperation from one period to the next is 0.475 , significant at $p=0.000$, which might indicate that one teammate's decision at host influences teammates who follow, or that the effects we find are inducing a correlation in behavior of different participants when they are in the same environment. However, the correlation between guest cooperation from one period to the next is even slightly higher, at 0.495 (also significant at $p=$ 0.000). Since one does not observe one's teammates' play as guests, in this case there is no mechanism for influence. The other possible transmission channel is through the observation of the visitor choices in one's own room; while this could affect behavior when away, it would seem more likely that the channel of influence runs through observing one's group members rather than from observing strangers. Thus, we interpret this as evidence that host choices are no less independent than guest choices.

Finally we look at how behavior is affected by homogeneity and heterogeneity of gender composition of groups in the same experimental session. In Table 1, we see that males cooperate more when away by an average of 17.1 percentage points in the all-male sessions, as compared to 5.2 percentage points in the mixed-gender sessions. By comparison, there is little corresponding difference (14.6 percentage points versus 10.5 percentage points) for females across all-female and mixed-gender sessions. However, we do note that the overall rate of females choosing cooperation is higher when playing against males than against females. This is true both when at home $(50.0 \%$ versus $43.9 \%$ ) and when away (39.5\% vs. $29.3 \%$ ), although neither difference is statistically 
significant, nor is the difference found by pooling these data (the test of the difference of proportions gives $Z=1.20, p=0.230$ ). We do not observe this pattern for males, as they play slightly more cooperatively against females when at home, but less cooperatively against females when away.

\section{Theoretical Background}

Our experimental setup adds two different elements to a Prisoner's Dilemma game: the presence of a group watching the behavior of individuals, and the polar gender difference in the composition of the groups. There is evidence suggesting that both elements will affect behavior.

For the effect of group versus individual play, the risky-shift literature in social psychology (beginning with Stoner (1961)) hypothesizes that deliberation leads groups to make riskier decisions than the average of its individual members. Insko, Schopler, Hoyle, Dardis, and Graetz (1990) provide evidence of an individual-group discontinuity in behavior, with groups being more aggressive. Recent work (e.g., Charness, Rigotti, and Rustichini (2007)) has shown that group membership may affect decisions made by individual members, even in controlled laboratory environments in which participants have monetary incentives.

For the effect of gender composition of groups, a related literature indicates that women are less competitive than men. In the experiments underlying the studies, the environment is characterized by a payment scheme, which is called competitive if the payment depends on the performance of the individual relative to that of other participants. Findings (Gneezy, Niederle, and Rustichini (2003), Gneezy and Rustichini (2004), and Niederle and Vesterlund (2007)) show an improvement in performance with homogeneous gender groups when the payment scheme becomes competitive. This improvement is smaller for females, who are also less likely to choose a competitive scheme when they are given a choice. 
How should we expect these two elements, gender and audience, to interact? The literature providing an evolutionary foundation for gender differences in preferences (see Becker and Michael, (1973), Rubin and Paul (1979), Karni and Schmeidler, (1986), Robson (1996a), (1996b)), can provide some methodological insight. For example, the finding that females seem to be more risk averse has stimulated research trying to provide a foundation for selection of preferences. The main idea is that higher willingness to take risks is selected for players in games that have winner-take-all payoff structures, as with males in sexual competition (see for example Dekel and Scotchmer (1999) for a detailed analysis of this issue; see also Robson (1996a), Wärneryd (2002)). There is no similar research regarding the explanation of gender differences in behavior observed by in and out-groups. On the model of the literature on risk preferences, we suggest that a promising direction might be the following: Clearly, social behavior provides a signal of unobservable types to others; hence when players choose an action that is (as in our experiment with an audience) socially observable they will also take into account the signal that this action provides. A difference in social behavior across genders might be induced by different preferences over the social signal. What could be the reason for gender differences in such preferences?

Theories in social and evolutionary psychology provide a conceptual structure. Cross and Madson (1997) argue that important gender differences in social behavior may be explained by differences in the construction and maintenance of self-definition (self-construal, Markus and Kitayama (1991)): men rely on an independent self-construal, women an interdependent one. This view might suggest that social bonds and interactions are less important for men. In our experimental environment, this theory would predict that the male response would be independent of the nature of the audience composition, while the female response would not. Within the conceptual structure of Cross and Madson, however, Baumeister and Sommer (1997) argue that social bonds are instead 
equally important for men and women, but in a different way. Men seek social connections in larger groups, with the aim of achieving a favorable position in the social hierarchy, while women seek those connections in smaller, or even dyadic, relationships. ${ }^{1}$

In the specific environment of our experiment, when behavior is socially observable both males and females are likely to be concerned with the signal their social behavior sends to in-group members and potentially to out-group members; which attributes are deemed important may differ across gender. In same-gender sessions, males may prefer signaling to other in-group males that they are tough and that the male opponent cannot take advantage of them, in order to enhance their status in the group. In the Prisoner's Dilemma game this motivation makes the choice of defection more appealing: if the opponent defects, the player will not be seen to be a 'sucker', while if the opponent cooperates, the player will have a higher payoff than the opponent. This incentive would be weaker for males when away, so that the cooperation rate should increase. In mixed-gender sessions, when the male meets a female this incentive should be reduced, and so the difference in behavior when at home and when away should also be reduced.

In same-gender sessions, females may be inclined to signal to their in-group members their cooperative traits, more so than to female out-group members; this is because they rely on interdependence and interaction with the in-group members, but not with the out-group members. ${ }^{2}$ In the Prisoner's Dilemma game this motivation makes cooperation more appealing at home, since it

\footnotetext{
${ }^{1}$ These theories are developed as psychological theories, but the predictions have an established evolutionary foundation (as Baumeister and Sommer (1997, p. 39) also mention), both for males (Barkow (1975, 1989), Alexander (1987), Symons (1979), Ridley (1993), Buss (1994)) and females (Hrdy (1999, 2001, 2005, 2009)). For example, status and warriorship are highly correlated in two tribes of the Ecuadorian Amazon (Patton (2000)).

${ }^{2}$ A strong evolutionary reason for this can be seen in the work of Hrdy (1999, 2001, 2005, 2009), which emphasizes how the help of individuals (female and male) close to the mother (allomothers), had a critical role in child rearing, as opposed to early models of attachment in evolutionary psychology that saw the mother as the almost-exclusive caretaker (Ainsworth and Bowlby (1965), Bowlby (1969)). The help of allomothers would depend on reciprocal exchange, hence on the reputation that the mother had for cooperative behavior. This help would be coming from in-group members, and not from out-group ones, hence females would be less interested in signaling cooperative traits to out-group individuals, who would be less likely to offer help in the future.
} 
signals willingness to risk a low personal payoff in exchange for a possible higher joint payoff. Thus, the cooperation rate for females should fall in the away condition: and if the view presented in Cross and Madson holds at least partially, so that in-group bonds are stronger for females, then cooperation rate for females when away should be lower than for males when away.

In mixed-gender sessions, the additional motivation provided by the social signal would be weaker. For males, a display of tough behavior with a female should be less valuable if the motivation is status. For females, it should be less valuable to signal cooperative traits at home when the other player is an out-group male, since males who are not next of kin are less likely to be allomothers (as is documented among primates: Fairbanks and McGuire, (1993), Smith (2006)). In summary, the effects of an audience (of either type) should be weaker in mixed-gender sessions.

\section{Interpretation of results}

The important and significant patterns in our data are: 1) males cooperate less at home than when away, whereas females cooperate more at home than when away; 2) at home, the cooperation rate of females is higher than that of males; 3) when away, the two cooperation rates are similar. These patterns must be explained by a theory.

To get a richer picture, it is first interesting to compare our results with those for the same Prisoner’s Dilemma game reported in Charness, Rigotti, and Rustichini (2007). The subject pool in the two studies is the same (students at UCSB), so comparing the results is meaningful. The major difference between the designs of the two studies is in the gender composition of the groups. Each group in the comparable treatment in the earlier study was comprised of a mix of males and females, in similar proportions; overall, there were 41 male and 59 female participants. The male cooperation rate at home was $36.6 \%$, compared to $28.9 \%$ in the current study; the female cooperation rate was 
$35.6 \%$, compared to $45.8 \%$ in the current study. Thus, the cooperation rates with mixed-gender groups tend to be closer to the mean behavior, and there is no significant overall gender difference in behavior. The comparison between these results and ours suggests that gender composition of a group, rather than gender of the participant per se, affects behavior.

In Charness, Rigotti, and Rustichini (2007), sessions were also conducted in which no audience was present, so it was possible to check separately the effect of audience. The effect on behavior was significant at home, but not when away. The cooperation rate for participants at home with an in-group audience was $36.0 \%$ versus $56.7 \%$ with no audience $(Z=2.96, p=0.003)$; on the other hand, the cooperation rate with an out-group audience was $46.0 \%$ versus $48.1 \%$ with no audience $(Z=0.30, p=0.764)$. These results show that the outcome per se is not the only driving factor in one's decision when one's group members are present. They also suggest that the awareness that one's in-group members are observing is important, but whether members of the out-group are observing is less important.

The theory we examined assumes that males and females have different incentives regarding the signal they wish to send to the in-group and out-group members. The predictions of this theory fit most of the observed patterns. At home males have the additional motivation to signal to other ingroup males that they are tough; this motivation is weaker when they face out-groups, because they are less likely to establish hierarchical relations with them. Females instead wish to signal to other in-group females that they are cooperative, with a weaker motivation when facing out-group individuals. In our data we do observe that males play less cooperatively and females play more cooperatively in front of their peers. The cooperation rate should be closer amongst the two genders when away, since individuals are in both cases less interested in signals sent to strangers; or (in the Cross and Madson view that in-group bonds are relatively stronger for females) the cooperation rate 
should be lower for females when away, which is what we find. Overall cooperation rates for males and females when away are $42.1 \%$ and $32.5 \%$, respectively; while this difference is not significantly significant $(Z=1.52, p=0.129)$, in the same-gender sessions we have $44.7 \%$ versus $29.3 \%$, a significant difference $(\mathrm{Z}=2.02, p=0.044)$.

\section{Conclusion}

We report a qualitative and significant gender difference in cooperation rates in a prisoner's dilemma experiment. Individuals of different genders respond differently to an in-group or an outgroup audience watching their behavior: With an out-group audience, cooperation rates are similar for the two genders. However, females cooperate more with an in-group audience, while males cooperate less. The average overall cooperation rate is similar for the two genders, and in line with what had been found earlier. These results provide insight to the puzzle posed by existing literature regarding the lack of observed gender differences in social behavior.

The fact that differences are strong when participants play in front of the in-group audience, and are absent otherwise, strongly suggests that the signal sent to in-group members concerning social behavior is the driving force of the difference. The specific explanation we propose regarding the difference in behavior is that men prefer signaling to other members in their group that they are tough, while women prefer to signal they are inclined to cooperation. Extending these results to different game forms, thereby testing our proposed explanation, seems one of the most promising directions for future research. 


\section{References}

Ainsworth, M. and Bowlby, J., (1965), Child Care and the Growth of Love, London: Penguin Books. Alexander, R. D., (1987), The biology of moral systems, Hawthorne, NY: Aldine DeGruyter

Baumeister, R. \& Sommer, K. (1997), What do men want? Gender differences and two spheres of belongingness: Comment on Cross and Madson, Psychological Bulletin, 1, 122, 38-44.

Barkow, J. H., (1975), Prestige and culture: a biosocial interpretation (and replies), Current Anthropology, 16, 553-576.

Barkow JH. (1989). Darwin, sex and status, Toronto, University of Toronto Press.

Barkow, J. H., Cosmides, L., Tooby, J. (eds), (1992), The adapted mind, New York: Oxford University Press.

Becker, G.S., Michael, R.T., (1973), On the new theory of consumer behavior, Swedish Journal of Economics, 75, 378-395.

Bowlby J (1999). Attachment. Attachment and Loss, vol. 1; 2nd ed.: New York: Basic Books.

Charness, G. \& Gneezy, U. (2007), Strong Gender Differences in Investment, mimeo.

Charness, G., Rigotti, L. \& Rustichini, A. (2007), Individual Behavior and Group Membership, American Economic Review, 97, 1340-1352.

Croson R., Gneezy, U., (2009) Gender Differences in Preferences, Journal of Economic Literature, 47, 2, 448-74.

Cross S. E. and Madson, L. (1997), Models of the Self: Self-Construals and Gender, Psychological Bulletin, 1, 5-37.

Dekel, E. and Scotchmer, S., (1999), On the evolution of attitudes towards risk in winner-take-all games, Journal of Economic Theory, 87, 125-143.

Glasnapp, D. and Poggio, J. (1985), Essentials of Statistical Analysis for the Behavioral Sciences, Merrill: Columbus.

Fairbanks, L. A. and McGuire, M. T., (1993), Maternal protectiveness and response to the unfamiliar in vervet monkeys, American Journal of Primatology, 30, 2, 119-129

Flynn,J., Slovic, P., Mertz, C. K., Gender, race and perception of environmental health risk, Risk Analysis, 14, 1101-1108.

Gneezy, U., Niederle, M. and Rustichini, A., (2003), Performance in competitive environments: Gender differences, Quarterly Journal of Economics, 118, 1049-1074.

Gneezy, U. and Rustichini, A., (2004), Gender and competition at a young age, American Economic Review, Papers and Proceedings, 94, 377-381.

Hrdy, S. (1999), Mother Nature: Maternal Instincts and How They Shape the Human Species, Ballantine Publishing Books, The Random House, New York.

Hrdy, S., (2001), The Past, Present and Future of the Human Family, The Tanner Lectures on Human Values, University of Utah.

Hrdy, S., (2005), Evolutionary Context of Human Development: the Cooperative Breeding Model, in: The 92nd Dahlem Workshop Report, Attachment and Bonding: A New Synthesis, C. S. Carter, L. Ahnert, K. E. Grossmann, S. B. Hrdy, M. E. Lamb, S. W. Porges, and N. Sachser editors, MIT Press

Hrdy, S., (2009), Mothers and Others: The Evolutionary Origins of Mutual Understanding Belknap Press, Harvard University Press, Cambridge MA.

Insko, C., Schopler, J., Hoyle, R., Dardis, G., Graetz, K. (1990), Individual-Group Discontinuity as a Function of Fear and Greed, Journal of Personality and Social Psychology, 58, 68-79.

Karni, E., Schmeidler, D., (1986), Self-preservation as a foundation of rational behavior under risk, 
Journal of Economic Behavior and Organization, 7, 71-81.

Kuwabara, K. (2005), Nothing to Fear But Fear Itself: Fear of Fear, Fear of Greed and Gender Effects in Two-Person Asymmetric Social Dilemmas, Social Forces, 84, 1257-1272.

Ledyard, J., (1995), Public Goods: a Survey of Experimental Results, in Handbook of Experimental Economics, edited by J. Kagel and A. E. Roth, Princeton University Press, 111-194.

Markus H. R. and Kitayama, S., (1991), Culture and the Selg: Implications for cognition, emotion and motivation, Psychological Review, 98, 224-253

Niederle, M. \& Vesterlund, L. (2007), Do Women Shy away from Competition? Do Men Compete too Much?, Quarterly Journal of Economics, 122, 1067-1101.

Patton, J. Q., (2000), Reciprocal Altruism and Warfare, A Case from the Ecuadorian Amazon, in Adaptation and Human Behavior: an Anthropological Perspective, Cronk, L., Chagnon, N. A. and Irons, William, Hawthorn NY: Aldine DeGruyter

Rapoport, A. and Chammah, A., (1963), Prisoner's Dilemma, University of Michigan Press

Ridley, M., (1993), The red queen: sex and the evolution of human behaviour, London, Viking.

Robson, A.J., (1996a), The evolution of attitudes to risk: Lottery tickets and relative wealth, Games and Economic Behavior, 14, 190-207.

Robson, A.J., (1996b), A biological basis for expected and non-expected utility, Journal of Economic Theory, 68, 397-424.

Rogers, A.R. (1994), Evolution of time preference by natural selection, American Economic Review, 84, 460-481.

Rubin, P.H. and Paul, C.W. II, (1979), An evolutionary model of taste for risk, Economic Inquiry, 17, 585-596.

Sell, J. (1997), Gender, Strategies, and Contributions to Public Goods, Social Psychology Quarterly, 60, 252-265

Siegel, S. \& Castellan, N. (1988), Nonparametric Statistics for the Behavioral Sciences, McGrawHill: Boston

Simpson, B. (2003), Sex, fear, and greed: A social dilemma analysis of gender and cooperation, Social Forces, 82, 35-52.

Smith, H. J., (2006), Parenting for primates, Harvard University Press, Cambridge.

Spigner, C., Hawkins, W. and Lorens, W., (1993), Gender differences in perception of risk associated with alcohol and drug use among college students, Women and Health, 20, 87-97.

Stoner, J. (1961), A Comparison of Individual and Group Decisions involving Risk, Unpublished Master's Thesis, School of Industrial Management, Massachusetts Institute of Technology.

Symons, D., (1979), The evolution of human sexuality, Oxford University Press.

Wärneryd, K. (2002), Rent, risk and replication: Preference Adaptation in winner-take-all markets, Games and Economic Behavior, 41, 344-364 


\title{
Appendix A - Instructions
}

\author{
INSTRUCTIONS (room R)
}

Thank you for participating in this experiment. You will receive \$5 for your participation, in addition to other money to be paid as a result of decisions made in the experiment.

There are 20 people participating in this session. They have been randomly divided into two rooms, each with 10 people. You are in room $\mathbf{R}$, this means you are a Row decider.

There will be ten rounds in this session, and each person will make two decisions, one in each room. You have a card with a green number and a card with a (different) yellow number. These numbers will determine when and where you make decisions.

Your green number indicates the round during which it will be your turn to make a decision in the room where you are now (room $R)$.

Your yellow number indicates the round during which it will be your turn to go to the other room (room C) and make a decision there.

In each round there are two people making a decision. Each person will be making a simultaneous choice between A and B in the following decision matrix:

\begin{tabular}{|c|c|c|c|}
\hline & \multicolumn{2}{|c|}{ Column } \\
\hline & & A & B \\
\hline & A & 5,5 & 1,7 \\
\hline Row & B & 7,1 & 2,2 \\
\hline
\end{tabular}

In each cell, the first number represents the outcome for the Row decider and the second number represents the outcome for the Column decider.

Thus, if both people choose A, the Row decider receives 5 and the Column decider receives 5 . If both people choose $B$, the Row decider receives 2 and the Column decider receives 2 . If the Row decider chooses $\mathrm{A}$ and the Column decider chooses $\mathrm{B}$, the Row decider receives 1 and the Column decider receives 7. If the Row decider chooses $B$ and the Column decider chooses A, the Row decider receives 7 and the Column decider receives 1 .

The other nine members of each room also have a financial stake in the outcome - each person not making a decision receives $1 / 3$ of the amount shown for the realized outcome.

Thus, if both deciders choose A, every inactive person in room $\mathrm{R}$ receives $5 / 3$ and every inactive person from room $C$ receives $5 / 3$. If both deciders choose $B$, every inactive person from room $R$ 
receives $2 / 3$ and every inactive person from room $C$ receives $2 / 3$. If the Row decider chooses $A$ and the Column decider chooses $B$, every inactive person from room $R$ receives $1 / 3$ and every inactive person from room $\mathrm{R}$ receives $7 / 3$. If the Row decider chooses $\mathrm{B}$ and the Column decider chooses $\mathrm{A}$, every inactive person from room $\mathrm{R}$ receives $7 / 3$ and every inactive person from room $\mathrm{R}$ receives $1 / 3$.

Each unit is worth $\$ 0.50$ in actual money (2 units $=\$ 1$ ) that will be paid in cash at the end of the experiment.

All people in the room (except for the person from the other room) will be able to watch the decider who belongs to their room make his or her choice (however, no verbal comments are permitted).

The decision of the person who walks into the room, on the other hand, is made privately.

The outcome of the joint decision is immediately revealed to all people in the room.

After the 10 rounds are completed, we will total each person's earnings (from the outcomes of the two self-made decisions, as well as the other 18 outcomes), add the $\$ 5$ show-up fee, and pay each person individually and privately, using the numbers on your two cards to identify your decisions.

Please feel free to ask questions. 


\section{Appendix B - Session-level data}

\section{Cooperation Rates for Males}

\begin{tabular}{|c|c|c|c|}
\hline & Home & Away & Combined \\
\hline All-male sessions & & & \\
\hline Session 1 & $2 / 16(12 \%)$ & $7 / 16(44 \%)$ & $9 / 32(28 \%)$ \\
\hline Session 2 & $5 / 16(31 \%)$ & $7 / 16(44 \%)$ & $12 / 32(38 \%)$ \\
\hline Session 3 & $4 / 16(25 \%)$ & $5 / 16(31 \%)$ & $9 / 32(28 \%)$ \\
\hline Session 4 & $5 / 14(36 \%)$ & $8 / 14(57 \%)$ & $13 / 28(46 \%)$ \\
\hline Session 5 & $5 / 14(36 \%)$ & $7 / 14(50 \%)$ & $12 / 28(43 \%)$ \\
\hline MF sessions & & & \\
\hline Session 1 & $1 / 10(10 \%)$ & $2 / 10(20 \%)$ & $3 / 20(15 \%)$ \\
\hline Session 2 & $3 / 8(38 \%)$ & $4 / 8(50 \%)$ & $7 / 16(44 \%)$ \\
\hline Session 3 & $2 / 6(33 \%)$ & $2 / 6(33 \%)$ & $4 / 12(33 \%)$ \\
\hline Session 4 & $2 / 6(33 \%)$ & $3 / 6(50 \%)$ & $5 / 12(41 \%)$ \\
\hline Session 5 & $4 / 8(50 \%)$ & $3 / 8(38 \%)$ & $7 / 16(44 \%)$ \\
\hline
\end{tabular}

Cooperation Rates for Females

\begin{tabular}{|c|c|c|c|}
\hline & Home & Away & Combined \\
\hline All-female sessions & & & \\
\hline Session 1 & $11 / 20(55 \%)$ & $6 / 20(30 \%)$ & $17 / 40(42 \%)$ \\
\hline Session 2 & $6 / 14(43 \%)$ & $3 / 14(21 \%)$ & $9 / 28(32 \%)$ \\
\hline Session 3 & $4 / 12(33 \%)$ & $5 / 12(42 \%)$ & $9 / 24(38 \%)$ \\
\hline Session 4 & $10 / 16(62 \%)$ & $4 / 16(25 \%)$ & $14 / 32(44 \%)$ \\
\hline Session 5 & $5 / 20(25 \%)$ & $6 / 20(30 \%)$ & $11 / 40(28 \%)$ \\
\hline MF sessions & & & \\
\hline Session 1 & $5 / 10(50 \%)$ & $4 / 10(40 \%)$ & $9 / 20(45 \%)$ \\
\hline Session 2 & $3 / 8(38 \%)$ & $2 / 8(25 \%)$ & $5 / 16(31 \%)$ \\
\hline Session 3 & $3 / 6(50 \%)$ & $3 / 6(50 \%)$ & $6 / 12(50 \%)$ \\
\hline Session 4 & $4 / 6(67 \%)$ & $3 / 6(50 \%)$ & $7 / 12(58 \%)$ \\
\hline Session 5 & $4 / 8(50 \%)$ & $3 / 8(38 \%)$ & $7 / 16(44 \%)$ \\
\hline
\end{tabular}

